\title{
Reasons for the Underutilization of Generic Drugs by US Ophthalmologists: A Survey
}

Jamie Dietze (D) - Aaron Priluck · Robin High $\cdot$ Shane Havens

Received: June 17, 2020 / Published online: August 19, 2020

(C) The Author(s) 2020

\begin{abstract}
Introduction: Cross-sectional survey of 92 board-certified practicing Midwestern ophthalmologists to determine why prescribing habits favor brand-name drugs over generics and to identify approaches for increasing generic drug utilization.

Methods: A survey was sent to members of state ophthalmology societies, private practice groups, and individual ophthalmologists to evaluate basic demographic/practice information, knowledge and opinions on generic drugs, frequency of drug representative visits, understanding of the Food and Drug Administration's process of evaluating generics, knowledge of patients' financial status and preferences, and action items that would increase generic utilization.
\end{abstract}

Digital Features To view digital features for this article go to https://doi.org/10.6084/m9.figshare.12760226.

J. Dietze $(\varangle) \cdot$ A. Priluck $\cdot$ R. High $\cdot$ S. Havens University of Nebraska Medical Center, Omaha, NE, USA

e-mail: jamie.dietze@gmail.com

J. Dietze

West Virginia University Medicine, Morgantown, WV, USA

A. Priluck

Johns Hopkins Medicine, Baltimore, MD, USA
Results: Three factors increase the likelihood of ophthalmologists switching patients to generic drugs: increased knowledge of (1) generic options, (2) price differences between brandnames and generics, and ((3) patient preference for generics. The following four factors decrease the likelihood of ophthalmologists switching patients to generic drugs: (1) increased disease severity, (2) feeling that patient outcomes may be affected by choice of brand-name versus generic, (3) personal preference for taking a brand-name drug over a generic for their own hypothetical eye disease even if both were free, and (4) increased personal preference for taking a brand-name drug for their hypothetical eye disease.

Conclusion: Ophthalmologists should continue to update themselves on generic medication options, become familiar with the price difference of generics versus brand-name drugs for commonly prescribed medications, and seek patients' opinions on generics and correct them when possible to increase generic utilization. In addition, studies evaluating the clinical equivalence of generic drugs relative to brand-name drugs should be performed and may help increase generic utilization.

Keywords: Generic utilization; Medication costs; Ophthalmic drugs; Physician bias; Prescribing habits 


\section{Key Summary Points}

Prescription drug spending is a significant percentage of the healthcare cost to patients and the healthcare system, and it is especially important in the field of ophthalmology, as many conditions are managed with pharmacotherapy to prevent or slow visual impairment.

It is important to identify any modifiable factors that could decrease costs for patients to help lessen the risk of becoming visually impaired and the cost burden on the healthcare system.

This study sought to understand why ophthalmologists hesitate to prescribe generics and what encourages them to do so through anonymous survey questioning.

Ophthalmologists should be aware of generic options, become familiar with the price difference of generics versus brandname drugs for commonly prescribed medications, and seek patients' opinions on generics and correct them when possible to increase generic utilization.

There are several possible modifiable factors that both patients and prescribers can change that could help to increase the amount of generic drug utilization and therefore decrease the overall healthcare cost.

\section{INTRODUCTION}

Generic medications are approved by the Food and Drug Administration as having the same high quality, strength, purity, and stability as brand-name medications. Generic drugs are considered to be just as safe and effective as their brand-name counterparts and typically cost less [1]. Generic medicines contain the same active ingredient(s) as their brand-name counterparts and are used at the same dosage to treat the same diseases. To help minimize medical costs and decrease the likelihood of patients stopping medications due to financial burden, generic utilization has been encouraged when possible [2]. Prescription drug spending is a significant percentage of the healthcare cost to patients and the United States healthcare system [3]. Utilization of generic medications is highly variable among different countries across the globe, but many have a much higher percentage of generic usage as compared to the United States [4]. Prescription drug spending accounted for $\$ 333.4$ billion of the national healthcare expenditure in the United States in 2017, and continues to rise every year [5]. However, clinicians are not always aware of the cost burden to their patients. In a nationwide survey of chronically ill older adults, $66 \%$ of those who reported underuse of their medications due to cost concerns never informed their clinician that they did not intend to adhere to the medication regimen, and 35\% never discussed the issue of cost concern at all [6]. This implies that clinicians must address this disparity, as patients have not been voicing their concerns. It is especially important in the field of ophthalmology because many conditions are managed with pharmacotherapy to prevent or slow visual impairment. Once a patient is visually impaired, studies have shown that there is a significant increase in their economic burden that is far greater than when they were on preventive treatment [7]. Therefore, it is important to identify any modifiable factors to decrease the number of patients that become visually impaired, from both an individual and national healthcare cost standpoint.

Medicare Part D data show that ophthalmologists prescribe a larger percentage of brandname medications than other fields of medicine [8]. This is partly due to the lack of generic alternatives for certain medications; however, we sought to identify other potential underlying reasons. This is the first study to survey ophthalmologists' views on generic drugs in order to identify ways to increase generic utilization. Previous studies have identified negative opinions regarding the efficacy of generic medications among non-ophthalmologist 
physicians and the general public [9]. We hypothesized that ophthalmologists may also have some negative opinions of generic medications that may help explain the relatively low rate of generic prescriptions. Identifying negative perceptions of generic drugs and characteristics of ophthalmologists who have those perceptions may help tailor educational interventions and craft drug policy changes that would result in high-quality care while minimizing cost [9].

This study surveyed 92 board-certified ophthalmologists currently practicing in the Midwestern United States regarding their views of brand-name and generic medications to identify possible underlying factors influencing prescribing habits.

\section{METHODS}

A standardized cross-sectional survey was provided to currently practicing, board-certified ophthalmologists, along with an institutional review board (IRB)-approved consent letter to those located in the Midwest region of the United States. We focused on a regional survey to better assess what might need to be explored in a larger, national survey. This study was performed in accordance with the Helsinki Declaration of 1964, and its later amendments. All subjects provided informed consent to participate in the study, and no identifying information is included in the manuscript. The study was approved by the University of Nebraska Medical Center Institutional Review Board. The surveys were distributed and collected electronically through Google Forms from July 2018 through April 2019, as electronic survey was deemed the best way to collect survey data from medical providers as shown in the study by Cunningham et al. [10]. The Midwest region was defined as including the states of North Dakota, South Dakota, Nebraska, Kansas, Minnesota, Iowa, Missouri, Wisconsin, Illinois, Indiana, Michigan, and Ohio [11]. Physicians were not provided with any benefits or incentives for taking the survey, and responses were anonymous. Responders self-reported all information given, and answers were assumed to be honest and accurate. Ophthalmologists were contacted via email, online office contact forms, or via individual state ophthalmology societies willing to participate. We asked all 12 state societies and private practice groups within those states to send our survey to their members. The state societies reached out to over 700 ophthalmologists. In addition, 374 individual ophthalmologists practicing at academic institutions in the Midwest were contacted directly by email. The questions asked of participants are summarized, along with results, in Table 1. Overall, questions were related to ophthalmologists' views or knowledge of the following with regard to brand-name versus generic drugs: cost, quality/safety, patient feedback, whether disease severity impacts drug choice, and current prescribing choices including reason(s) for doing so. Responses to questions were generally in the form of a Likert scale or one or more multiple-choice options.

The survey collected several types of ordinal data (most with five levels). Data were summarized in tables with a cross-classification of the counts of pairs of the factors of interest. In particular, switching from brand-name to generic drugs was examined with several types of patient and drug characteristics. Spearman correlations were computed as the primary measure of association, along with exact Chi-Square test for the $p$ values of independence. Other summary measures (e.g., gamma, Kendall's tau, Somers' D) were also applied, with similar results. Statistical analyses were generated with PROC FREQ from SAS/STAT software, version 9.4 (C 2002-2012) of the SAS System for Windows (Cary, NC).

\section{RESULTS}

Five of the 12 state ophthalmology societies (Nebraska, Minnesota, South Dakota, North Dakota, and Wisconsin) and eight private practice groups sent our survey to their currently practicing, board-certified physicians. Ninety-two responses were collected, and all were included in our analysis.

All participants graduated from residency between 1973 and 2018 and attended programs 
Table 1 Survey questions and aggregate responses

\begin{tabular}{|c|c|c|}
\hline Question & Average $\pm \mathrm{SD}($ or $N(\%)$ when applicable $)$ & Notes \\
\hline 1. Age & $49.3 \pm 12.6$ & $\begin{array}{l}\text { Multiple-choice question } \\
\text { allowing one answer (ages } 28 \\
\text { through } 100 \text { allowed) }\end{array}$ \\
\hline 2. Gender & $\begin{array}{l}\text { Male: } 60(65.2 \%) \\
\text { Female: } 29(31.5 \%) \\
\text { Prefer not to say: } 3(3.3 \%)\end{array}$ & Multiple-choice question \\
\hline 3. Residency graduation year & $2000.3 \pm 13.4$ & $\begin{array}{l}\text { Multiple-choice question } \\
\text { allowing one answer (years } \\
1948 \text { through 2018) }\end{array}$ \\
\hline 4. US area of residency completion & $\begin{array}{l}\text { Midwest: } 56 \text { (60.9\%) } \\
\text { Northeast: } 17(18.5 \%) \\
\text { Southeast: } 8(8.7 \%) \\
\text { Southwest: } 8 \text { (8.7\%) } \\
\text { Northwest: } 3(3.3 \%)\end{array}$ & $\begin{array}{l}\text { Multiple-choice question } \\
\text { allowing one answer }\end{array}$ \\
\hline 5. Primary area of specialization & $\begin{array}{l}\text { General ophthalmology: } 21 \text { (22.8\%) } \\
\text { Cornea/external eye disease: } 20(21.7 \%) \\
\text { Glaucoma: }(18,19.6 \%) \\
\text { Retina: } 16(17.4 \%) \\
\text { Pediatrics: } 8(8.7 \%) \\
\text { Neuro-ophthalmology: } 5(5.4 \%) \\
\text { Oculoplastics: } 3(3.3 \%) \\
\text { Uveitis: } 1(1.1 \%)\end{array}$ & $\begin{array}{l}\text { Multiple-choice question } \\
\text { allowing one answer }\end{array}$ \\
\hline $\begin{array}{l}\text { 6. How many patients do you see on a } \\
\text { normal clinic day? }\end{array}$ & $\begin{array}{l}<15: 3(3.3 \%) \\
\text { 16-20: } 6(6.5 \%) \\
\text { 21-25: } 10(10.9 \%) \\
\text { 26-30: } 21(22.8 \%) \\
\text { 31-35: } 15(16.3 \%) \\
\text { 36-40: } 17(18.5 \%) \\
>41: 20(21.7 \%)\end{array}$ & $\begin{array}{l}\text { Multiple-choice question } \\
\text { allowing one answer }\end{array}$ \\
\hline 7. Do you perform surgical procedures? & $\begin{array}{l}\text { Yes: } 81(88 \%) \\
\text { No: } 11(12 \%)\end{array}$ & $\begin{array}{l}\text { Multiple-choice question } \\
\text { allowing one answer }\end{array}$ \\
\hline
\end{tabular}


Table 1 continued

\begin{tabular}{lll}
\hline Question & Average \pm SD (or $N(\%)$ when applicable) & Notes \\
\hline
\end{tabular}

8. Do you feel that patient compliance is

Yes, my patients are more compliant when

Multiple-choice question affected by generic usage vs. brand name? using generics: 20 (21.7\%) allowing one answer

Yes, my patients are more compliant when using brand names: 1 (1.1\%)

No, my patient compliance is not affected to my knowledge: 53 (57.6\%)

I have never looked into it: 18 (19.6\%)

9. Which classes of drugs do you feel

Antibiotic-drops: 86 (93.5\%) comfortable with prescribing generics over brand name? (all are drops unless otherwise indicated)

Antibiotic-oral: 87 (94.6\%)

Steroid-drops: 78 (84.8\%)

Multiple-choice question allowing one or more answers

Steroid-oral: 84 (91.3\%)

Beta blocker: 84 (91.3\%)

Carbonic anhydrase inhibitors: 82 (89.1\%)

Prostaglandin analogs: 80 (87.0\%)

Alpha agonists: 74 (80.4\%)

Antihistamine: 72 (78.3\%)

Antifungal: 46 (50\%)

Sympathomimetics: 58 (63\%)

Parasympathomimetics: 58 (63\%)

Artificial tears: 66 (71.7\%)

None: 1 (1.1\%)

10. How often do drug representatives visit Never: 27 (29.3\%) your clinic?

$1-4$ times per year: $22(23.9 \%)$

Multiple-choice question allowing one answer

1-2 times per month: 23 (25.0\%)

1-2 times per week: $11(12.0 \%)$

$>2$ times per week: 9 (9.8\%)

11. How well do you feel you know the

Practically not at all (1): 3 (3.3\%)

Likert scale from 1 to 5 availability of generic options for drugs you commonly prescribe?

2: $4(4.3 \%)$

3: $14(15.2 \%)$

4: $34(37.0 \%)$

Extremely well (5): 37 (40.2\%) 
Table 1 continued

\begin{tabular}{lll}
\hline Question & Average \pm SD (or $N(\%)$ when applicable) & Notes \\
\hline 12. How well do you feel you know the & Practically not at all (1): 11 (12.0\%) & Likert scale from 1 to 5 \\
price differences between generics and & 2: $14(15.2 \%)$ & \\
brand-name drugs you commonly & $3: 33(35.9 \%)$ & \\
prescribe? & $4: 27(29.3 \%)$ & \\
& Extremely well (5): $7(7.6 \%)$ & \\
& Never $(1): 8(8.7 \%)$ & \\
13. Do you often try to switch patients scale from 1 to 5 \\
from brand-name drugs to generic drugs? & 2: $9(9.8 \%)$ & \\
& $3: 26(28.3 \%)$ & \\
& $4: 39(42.4 \%)$ & \\
& Always $(5): 10(10.9 \%)$ & \\
\hline
\end{tabular}


Table 1 continued

\begin{tabular}{|c|c|c|}
\hline Question & Average \pm SD (or $N(\%)$ when applicable) & Notes \\
\hline $\begin{array}{l}\text { 14. Do you have any reservations about } \\
\text { prescribing a generic drug in place of a } \\
\text { brand-name drug? Check all that apply }\end{array}$ & 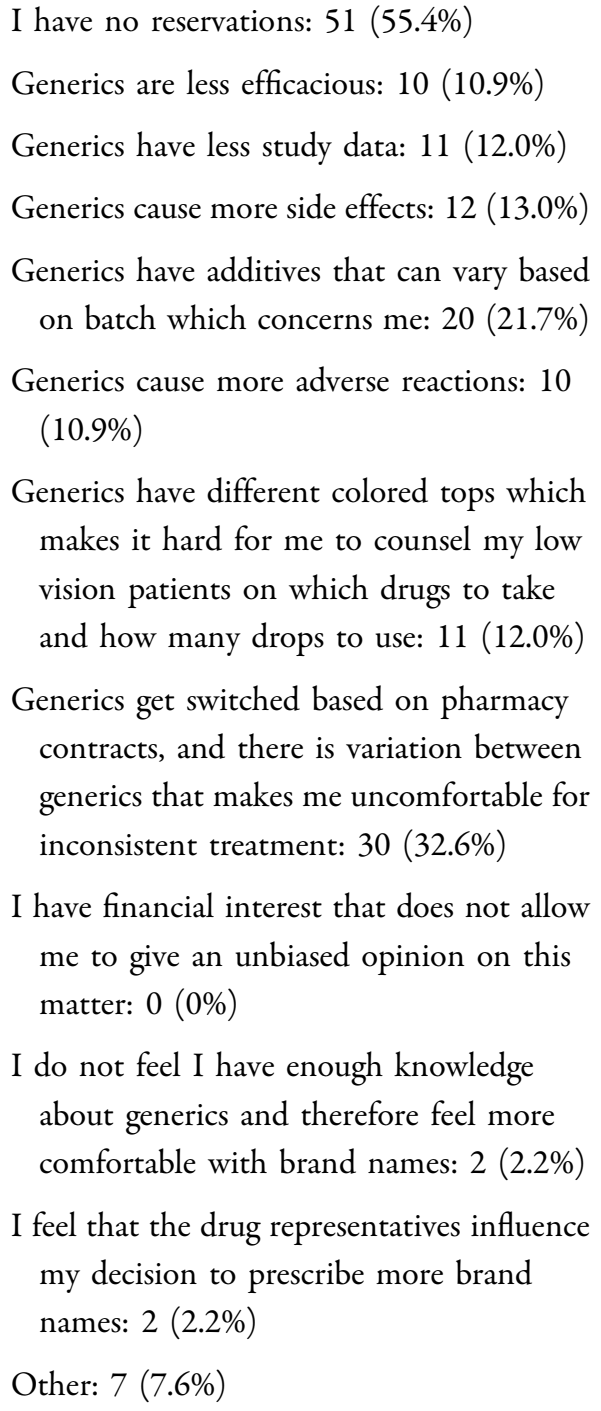 & $\begin{array}{l}\text { Multiple-choice question } \\
\text { allowing one or more } \\
\text { answers }\end{array}$ \\
\hline $\begin{array}{l}\text { 15. Do you know the difference in the } \\
\text { approval process by the Food and Drug } \\
\text { Administration for generic versus brand- } \\
\text { name drugs? }\end{array}$ & $\begin{array}{l}\text { I am not aware of a difference }(1): 20 \\
(21.7 \%) \\
\text { 2: } 13(14.1 \%) \\
\text { 3: } 18(19.6 \%) \\
\text { 4: } 32(34.8 \%) \\
\text { I understand it very well }(5): 9(9.8 \%)\end{array}$ & Likert scale from 1 to 5 \\
\hline
\end{tabular}


Table 1 continued

\section{Question}

16. Do you feel that you are aware of which patients are struggling financially?

\section{Average \pm SD (or $N(\%)$ when applicable) Notes}

Practically not at all (1): $2(2.2 \%)$

Likert scale from 1 to 5

2: $9(9.8 \%)$

3: $38(41.3 \%)$

4: $32(34.8 \%)$

Extremely Well (5): 11 (12.0\%)

17. Do you feel your patients prefer generic drugs over brand-name drugs? Put 3 if you are unsure of any preference

My patients prefer brand-name drugs (1): 0

Likert scale from 1 to 5 (0\%)

2: $5(5.4 \%)$

3: $35(38 \%)$

4: $31(33.7 \%)$

My patients prefer generic drugs (5): 21 (22.8\%)

18. Does the severity of your patient's disease make you more inclined to prescribe a brand-name drug over a generic?

Practically not at all (1): 31 (33.7\%)

2: $17(18.5 \%)$

3: $23(25.0 \%)$

4: $18(19.6 \%)$

Extremely well (5): 3 (3.3\%)

19. If severity does impact your decision, which is the correct reasoning you have for doing so?

If disease is more severe, I prescribe a brand name: $25(30.1 \%)$

If disease is more severe, I prescribe a generic: $0(0 \%)$

If disease is more severe, then I have less preference for brand vs. generic than I do when the disease is less severe: $2(2.4 \%)$

Severity does not impact my decision: 56 (67.5\%)

20. Do your patients ask about whether a Never (1): 20 (21.7\%) Likert scale from 1 to 5
Likert scale from 1 to 5 , with 1 being "never" and 5 being "always"

Multiple-choice question allowing one answer new drug being prescribed is a generic or brand name?

2: $29(31.5 \%)$

3: $21(22.8 \%)$

4: $19(20.7 \%)$

Always 5: $3(3.3 \%)$ 
Table 1 continued

\begin{tabular}{|c|c|c|}
\hline Question & Average $\pm \mathrm{SD}$ (or $N(\%)$ when applicable) & Notes \\
\hline $\begin{array}{l}\text { 21. Do you (anecdotally) feel that patient } \\
\text { outcome is affected by whether the brand } \\
\text { name of a drug is used as opposed to its } \\
\text { corresponding generic? Put } 3 \text { if you do } \\
\text { not feel there is any difference in outcome }\end{array}$ & $\begin{array}{l}\text { Better outcomes with generics (1): } 1 \text { (1.1\%) } \\
\text { 2: } 1(1.1 \%) \\
\text { 3: } 72(78.3 \%) \\
\text { 4: } 18(19.6 \%) \\
\text { Better outcomes with brand-names (5): } 0 \\
(0.0 \%)\end{array}$ & Likert scale from 1 to 5 \\
\hline $\begin{array}{l}\text { 22. If you had an eye disease, would you } \\
\text { rather take a brand-name drug or a } \\
\text { generic drug if both were FREE? Put } 3 \text { if } \\
\text { you have no preference }\end{array}$ & $\begin{array}{l}\text { Generic drug }(1): 2(2.2 \%) \\
2: 1(1.1 \%) \\
\text { 3: } 36(39.1 \%) \\
\text { 4: } 13(14.1 \%) \\
\text { Brand-name drug (5): } 40(43.5 \%)\end{array}$ & Likert scale from 1 to 5 \\
\hline $\begin{array}{l}\text { 23. If you had an eye disease, would you } \\
\text { rather take a brand-name drug or a } \\
\text { generic drug? Put } 3 \text { if you have no } \\
\text { preference }\end{array}$ & $\begin{array}{l}\text { Generic drug }(1): 10(10.9 \%) \\
\text { 2: } 7(7.6 \%) \\
\text { 3: } 40(43.5 \%) \\
\text { 4: } 20(21.7 \%) \\
\text { Brand-name drug (5): } 15(16.3 \%)\end{array}$ & $\begin{array}{l}\text { Likert scale from } 1 \text { to } 5 \text {, with } 1 \\
\text { being "generic drug" and } 5 \\
\text { being "brand-name drug" }\end{array}$ \\
\hline
\end{tabular}


Table 1 continued

\begin{tabular}{|c|c|c|}
\hline Question & Average \pm SD (or $N(\%)$ when applicable) & Notes \\
\hline $\begin{array}{l}\text { 24. I would prescribe more generics if: check } \\
\text { all that apply }\end{array}$ & $\begin{array}{l}\text { I would still exhibit the same prescribing } \\
\text { habits even if the following were done: } 34 \\
(37 \%) \\
\text { If more data was available on generic } \\
\text { efficacy: } 30 \text { ( } 32.6 \%) \\
\text { If I was more informed on the cost } \\
\text { difference: } 34 \text { ( } 37 \% \text { ) } \\
\text { If my patients asked for a generic: } 37 \\
\text { ( } 40.2 \%) \\
\text { If the generics had the same color tops as } \\
\text { the brand name type so I can counsel my } \\
\text { low vision patients the same with generics } \\
\text { as brand name: } 21 \text { ( } 22.8 \% \text { ) } \\
\text { If I knew my patient would stay on only } \\
\text { one generic brand rather than getting } \\
\text { switched based on pharmacy } \\
\text { contract/supply: } 41 \text { ( } 44.6 \% \text { ) } \\
\text { If more data was available on long-term side } \\
\text { effects/adverse reactions with generic } \\
\text { drugs: } 18 \text { ( } 19.6 \% \text { ) } \\
\text { are now: } 10 \text { ( } 10.9 \% \text { ) } \\
\text { situation: } 16 \text { ( } 17.4 \% \text { ) }\end{array}$ & $\begin{array}{l}\text { Multiple-choice question } \\
\text { allowing one or more } \\
\text { answers }\end{array}$ \\
\hline
\end{tabular}

from all regions of the US, with $61 \%$ completing residency in the Midwest; $65.2 \%$ of participants were male, $31.5 \%$ were female, and $3.3 \%$ preferred not to specify. Physician ages ranged from 31 to 76 years, averaging $49.3 \pm 12.6$ (SD). Participants represented the following sub-specializations: $22.8 \%$ general ophthalmology, $21.7 \%$ cornea/external eye disease, $19.6 \%$ glaucoma, $17.4 \%$ retina, $8.7 \%$ pediatrics, $5.4 \%$ neuro-ophthalmology, 3.3\% oculoplastics, and $1.1 \%$ uveitis. A large majority of those surveyed
(88\%) performed surgical procedures. Participants also reported how often drug representatives visited their clinic, with $29 \%$ reporting that they never visited. A total of $40.2 \%$ of ophthalmologists felt that they were extremely knowledgeable about the availability of generic options for drugs they commonly prescribed, and only $55.4 \%$ of ophthalmologists reported having no reservations about prescribing a generic drug in place of a brand-name drug. 
Each question asked and aggregate responses for each question are summarized in Table 1.

An exact Chi-Square test was used to analyze the relationship between the primary area of sub-specialization and how often ophthalmologists tried to switch patients to generic drugs. Due to low numbers of neuro-ophthalmology, oculoplastics, and uveitis specialists, they were excluded in the analysis. Our results showed that no particular sub-specialty was better (or worse) than any other in attempting to switch patients from brand-name to generic drugs $(p=0.38)$. Age and gender were also not influencing factors in the decision to switch from brand-name to generic drugs (odds ratio of 0.947 with confidence interval of $0.422-2.12$ for female versus male, and an odds ratio of 0.977 with $p=0.125$ for age).

The answers to numerical survey questions probing potentially modifiable factors were correlated with whether ophthalmologists often tried to switch patients to generic drugs, using a Spearman correlation coefficient. The results are shown in Table 2. A positive Spearman correlation coefficient indicates that the variable increases the likelihood that the ophthalmologist will try to switch patients to generic drugs. For example, a greater knowledge of the availability of generic options for commonly prescribed drugs (related to question 11) increases the chance that the physician will attempt to switch patients to generic options.

The frequency of drug representative visits was correlated with questions $12,15,17,21,22$, and 23 to gauge whether the physician's direct views on generics were related to the frequency of these visits. No statistically significant correlations were found, and all results are presented in Table 3.

The number of patients seen per day was correlated with questions 12 and 16 to gauge whether physicians responsible for more daily patient visits have relatively lower knowledge of price differences and their patients' financial situations. No statistically significant correlations were found, and these results are presented in Table 4.

\section{DISCUSSION}

All physicians strive to provide the best quality health care to their patients. One way to provide high-quality health care is to ensure that treatment options are affordable, in order to promote long-term medication adherence. The cost of medications can be a barrier to care in all of medicine including ophthalmology [12].

In an analysis of Medicare Part D data, the field of ophthalmology was found to prescribe a higher rate of brand-name drugs than any other specialty, and $\$ 148$ million would have been saved in 2013 (7\% savings) if generic and therapeutic substitutions had been made [13]. However, part of what drove the high rate of brand-name prescriptions was simply the lack of generic alternatives for certain commonly prescribed and expensive medications (e.g., cyclosporine) [8]. Indeed, another study found that the proportion of brand-name glaucoma medications prescribed when a generic formulation was available was very low in comparison to those classes with fewer generic alternatives, but still the generic prescription rate was only $75 \%$ at best in the 2018 Medicare Part D study [13]. However, it is difficult to ascertain whether such high generic utilization when available is due to physicians choosing the generic or whether it is secondary to substitution of brandname drugs with generics by pharmacies (laws vary by state as to how this is done).

Regardless, to maintain and increase the rate of generic prescriptions, we must understand why ophthalmologists hesitate to prescribe generics and what encourages them to do so. We found three variables that correlated with switching patients to generic drugs: increased knowledge of (1) generic options, (2) price differences between brand-name drugs and generics, and (3) patient preference for generic drugs. At the same time, ophthalmologists lack knowledge of each of those factors. Our study found that $22.9 \%$ of ophthalmologists reported 3 or lower on the Likert scale for knowledge about the availability of generic options, $63.1 \%$ reported 3 or lower for knowledge of the price differences between brand names and generics, and $38 \%$ were unsure whether patients 
Table 2 Correlation of whether ophthalmologists try to switch to generics with potentially modifiable variables; positive correlations indicate that as the variable increases, so does the inclination of the provider to switch to a generic drug

Variable (question number)

$\begin{aligned} & \text { Spearman correlation } \\ & \text { coefficient }\end{aligned}$
Result

Patients per day (6)

$\begin{array}{rl}-0.0408 & p=0.70 \\ 0.0166 & p=0.87 \\ 0.3129 & p=0.002 \\ 0.2904 & p=0.005\end{array}$

Knowledge of price differences between generics and brand-name drugs commonly prescribed (12)

Understanding of Food and Drug Administration approval process for generics $\quad-0.0138$

$p=0.90$ (15)

Awareness of which patients are struggling financially (16)

0.0154

$p=0.88$

Feeling that patients prefer generics (17)

$p<0.001$

Inclination to prescribe a brand-name drug for more severe disease (18)

$-0.3143$

$p=0.002$

Frequency of patients asking whether a new drug being prescribed is a generic or

0.0668

$p=0.53$

brand name (20)

Anecdotal feeling that patient outcome is improved with brand-name drugs (21) -0.4005

$p<0.001$

Desire to take a brand-name drug for own eye disease when free (22)

$-0.3197$

$p=0.002$

Desire to take a brand-name drug for own eye disease (23)

$-0.4213$

$p<0.001$

Table 3 Correlation of frequency of drug representative visits with knowledge and views of generic drugs; no statistically significant correlations were found

\begin{tabular}{lcc}
\hline Variable (question number) & $\begin{array}{l}\text { Spearman correlation } \\
\text { coefficient }\end{array}$ & $\boldsymbol{p}$ value \\
\hline $\begin{array}{l}\text { Knowledge of price differences between generics and brand-name drugs } \\
\text { commonly prescribed (12) }\end{array}$ & 0.1831 & $p=0.081$ \\
$\begin{array}{l}\text { Understanding of Food and Drug Administration approval process for generics } \\
\quad(15)\end{array}$ & 0.0506 & $p=0.63$ \\
$\begin{array}{l}\text { Feeling that patients prefer generics (17) } \\
\text { Anecdotal feeling that patient outcome is improved with brand-name drugs (21) }\end{array}$ & -0.0 .0158 & $p=0.31$ \\
$\begin{array}{l}\text { Desire to take a brand-name drug for own eye disease when free (22) } \\
\text { Desire to take a brand-name drug for own eye disease (23) }\end{array}$ & -0.0368 & $p=0.88$ \\
\hline
\end{tabular}


Table 4 Correlation of number of patients per day with financial knowledge; no statistically significant correlations were found

\begin{tabular}{lcc}
\hline Variable (question number) & $\begin{array}{l}\text { Spearman Correlation } \\
\text { coefficient }\end{array}$ & $\boldsymbol{p}$ value \\
\hline $\begin{array}{l}\text { Knowledge of price differences between generics and brand-name drugs } \\
\text { commonly prescribed (12) }\end{array}$ & 0.0783 & $p=0.46$ \\
\begin{tabular}{l} 
Awareness of which patients are struggling financially (16) \\
\hline
\end{tabular} & -0.0037 & $p=0.97$ \\
\hline
\end{tabular}

preferred generics. Thus, it is important to educate ophthalmologists at meetings and through publications on new generic options and the price differences between brand-name and generic drugs. Ophthalmologists should also probe patients' understanding and opinions regarding generic drugs. In fact, one study found that only $87 / 275$ (31.6\%) of office visits of glaucoma patients included a discussion regarding cost [14]. Knowing whether patients prefer a generic will help ensure it is prescribed. For patients who are hesitant to use generics, they can be further educated. The specific role that each of these individual variables plays and the increase in generic prescriptions that could be expected from increased education about them remains unknown.

We found four variables that decrease ophthalmologists' willingness to switch to generic drugs: (1) increased disease severity, (2) anecdotal feeling that patient outcome is affected by choice of brand name versus generic, (3) increased personal preference for taking a brand-name drug over a generic for their hypothetical eye disease when both drugs are free, and (4) increased personal preference for taking a brand-name drug over a generic for their hypothetical eye disease. There are currently very few studies demonstrating the equivalence of generics to their brand-name counterparts in ophthalmic medications. The FDA requires bioequivalence to be proven before generics are taken to market, but they do not undergo clinical trials like the brand-name drugs. Our study suggests there may be value in performing randomized clinical trials comparing generics to brand-name medications. Such trials may help alleviate the concern that brand- name drugs are more efficacious, which seems to be the underlying concern for all four variables found in our study. This makes sense, as obviously, not knowing about a generic option would prevent the ophthalmologist from prescribing it. Also, a greater inclination to prescribe a brand-name drug for more severe disease decreases the chance that the physician will attempt to switch patients to generic options.

The average number of patients seen per day, knowledge of the FDA approval process, knowledge of which patients were struggling financially, and whether patients asked whether a new drug was a generic did not significantly influence prescribing habits. The lack of correlation between the number of patients seen per day and prescribing habits is encouraging, as even busy clinics should be able to prescribe relatively high rates of generics if they choose to. The lack of correlation between knowledge of the FDA approval process and prescribing habits suggests that the current process to bring a generic drug to market is either not convincing or is too lenient when evaluating the equivalence of generic and brand-name drugs on average. In other words, physicians who understand the process better are not more likely to prescribe generic drugs, but neither are they more likely to prescribe brand-name drugs-while they do not seem to find the bioequivalence principle particularly convincing, they also do not find it concerning. Requiring clinical trials for generics would presumably decrease the number of generic drugs and increase their cost, but might also convince more physicians to use them; however, given the relatively high rates of generic utilization, 
this would very likely do more harm than good. Lastly, we found it surprising that neither knowledge of which patients are struggling financially nor whether patients inquired about whether a newly prescribed drug was a generic correlated with prescribing habits. This may be secondary to concerns of efficacy taking precedence over concerns of cost.

The frequency of drug representative visits did not alter ophthalmologists' understanding of the FDA approval process, awareness of whether patients preferred generics, anecdotal feeling about patient outcome on generics versus brand names, or desire to take a brand-name drug themselves. Past studies have shown an influence in brand-name drug preference secondary to the number of visits from drug representatives [15]. Given that all our responses were self-reported, it is possible that an objective analysis between these two variables would show a relationship. This may also simply be a weaker association than others and may only be identified in a larger study. Regardless, our results suggest that concerns about patients' health and well-being take precedence over potential influence by drug representatives.

Overall, 55.4\% of ophthalmologists had no reservations about prescribing a generic drug. Of the remaining $44.6 \%$ who had at least one reservation, the two most common concerns were (1) switching of generics based on pharmacy contracts and the variation between generics, and (2) the additives in generics that can vary based on production lots and manufacturers. Similarly, $44.6 \%$ of ophthalmologists surveyed indicated that they would increase generic prescriptions if they knew their patients would stay on only one generic rather than getting switched based on pharmacy contract and/or supply. Further studies investigating the equivalence of generics and clinical trials evaluating their efficacy may help alleviate these two primary concerns. Moreover, studies examining the consistency of generic formulations (and brand-name formulations) would shed light on this issue. Previous studies have found physical property differences in brandname drugs versus generics, but importantly, the clinical relevance of these differences in drug formulation was not investigated $[16,17]$.
Critical to this discussion is the recognition that physicians' perceptions of generic drugs are only a part of the equation; patients' perceptions and preferences also likely affect prescribing patterns. While $56.5 \%$ of ophthalmologists in our survey perceived that patients preferred generic drugs (marked 4 or 5 on question 17), with $38 \%$ feeling unsure whether patients had any preference, only $37 \%$ of patients were found to prefer generics in a survey study by Shrank et al. [18]. Our study found that patient preference appears to influence whether a generic is prescribed. Therefore, educating patients is critical to increasing generic drug utilization. This education may be especially important for patients in greater financial need, as one study found that patients in lower socioeconomic tiers have greater mistrust of generic drugs [2]. When our survey respondents were asked what would increase their rates of generic prescription, $40.2 \%$ responded that they would prescribe more generics if their patients simply asked.

Our study has limitations. First, it may not fully represent all board-certified ophthalmologists in the United States, as all respondents currently practice in the Midwest, and the response rate was limited, which is an increasingly common problem with medical survey studies [10]. We did ask personal opinions from ophthalmologists that may have been regarded as sensitive information by respondents, which may have lowered response rates, as seen in previous studies [10]. However, as was reported in the study by Kellerman, "physicians as a group are more homogeneous regarding knowledge, training, attitudes, and behavior than the general population," and therefore "nonresponse bias may not be as crucial in physician surveys as in surveys of the general population" [19]. We also did not ask whether participants worked primarily in an academic or private practice setting, though we believe the majority of our responses came from those working primarily in academic settings, as more surveys were sent to ophthalmologists at academic centers. Practice setting may be another factor that strongly influences prescribing habits. Moreover, some sub-specialties within ophthalmology were underrepresented, and 
lastly, and perhaps most importantly, survey answers are always subject to reporting bias.

\section{CONCLUSION}

Prescribing generic drugs is one way to reduce healthcare costs and may improve patient adherence. Our survey of 92 board-certified ophthalmologists currently practicing in the Midwestern United States revealed that the following three factors increased switching of patients to generic drugs: (1) increased knowledge of generic options, (2) increased knowledge of price differences between brand-name drugs and generics, and (3) increased knowledge of patient preference for generic drugs. The following four factors decreased ophthalmologist switching of patients to generic drugs: (1) increased disease severity, (2) anecdotal feeling that patient outcome is affected by choice of brand-name versus generic, (3) increased personal preference for taking a brand-name drug for hypothetical own eye disease when generics and brand names were free, and (4) increased personal preference for taking a brand-name drug for hypothetical own eye disease. Ophthalmologists should be aware of generic options, become familiar with the price difference of generics versus brand-name drugs for commonly prescribed medications, and seek patients' opinions on generics and correct them when possible to increase generic utilization. In addition, studies evaluating the consistency of generic drug formulations and the clinical equivalence of generic drugs relative to brandname drugs should be performed to help increase generic utilization. Hopefully, by pursuing these changes, we can increase the rate of generic prescriptions by ophthalmologists and make high-quality care more affordable for patients.

\section{ACKNOWLEDGEMENTS}

Funding. No funding or sponsorship was received for this study or publication of this article.
Authorship. All named authors meet the International Committee of Medical Journal Editors (ICMJE) criteria for authorship for this article, take responsibility for the integrity of the work as a whole, and have given their approval for this version to be published.

Disclosures. Jamie Dietze, Aaron Priluck, Robin High, and Shane Havens declare that they have no conflict of interest.

Compliance with Ethics Guidelines. This study was performed in accordance with the Helsinki Declaration of 1964, and its later amendments. All subjects provided informed consent to participate in the study, and no identifying information is included in the manuscript. The study was approved by the University of Nebraska Medical Center Institutional Review Board.

Data Availability. The data sets generated during and/or analyzed during the current study are available from the corresponding author on reasonable request.

Open Access. This article is licensed under a Creative Commons Attribution-NonCommercial 4.0 International License, which permits any non-commercial use, sharing, adaptation, distribution and reproduction in any medium or format, as long as you give appropriate credit to the original author(s) and the source, provide a link to the Creative Commons licence, and indicate if changes were made. The images or other third party material in this article are included in the article's Creative Commons licence, unless indicated otherwise in a credit line to the material. If material is not included in the article's Creative Commons licence and your intended use is not permitted by statutory regulation or exceeds the permitted use, you will need to obtain permission directly from the copyright holder. To view a copy of this licence, visit http:// creativecommons.org/licenses/by-nc/4.0/. 


\section{REFERENCES}

1. Center for Drug Evaluation and Research (2018, June 19) Patient Education. 2019. https://www.fda. gov/drugs/generic-drugs/patient-education. Accessed Apr 2019.

2. Dunne SS, Dunne CP. What do people really think of generic medicines? A systematic review and critical appraisal of literature on stakeholder perceptions of generic drugs. BMC Med. 2015;13:1. https://doi.org/10.1186/s12916-015-0415-3.

3. Kesselheim AS, Avorn J, Sarpatwari A. The high cost of prescription drugs in the United States. JAMA. 2016;316(8):858. https://doi.org/10.1001/jama. 2016.11237.

4. Wouters M. Comparing Generic Drug Markets in Europe and the United States: Prices, Volumes, and Spending. 2020. https://pubmed.ncbi.nlm.nih.gov/ 28895227/. Accessed 28 Jul 2020.

5. NHE. Fact Sheet-Centers for Medicare \& Medicaid Services. 2019. https://www.cms.gov/researchstatistics-data-and-systems/statistics-trends-andreports/nationalhealthexpenddata/nhe-fact-sheet. html. Accessed Apr 2019.

6. Tsai JC. A comprehensive perspective on patient adherence to topical glaucoma therapy. Ophthalmology. 2009;116:11. https://doi.org/10.1016/j. ophtha.2009.06.024.

7. Lafuma A, Brezin A, Lopatriello S, Hieke K, Hutchinson J, Mimaud V, Berdeaux G. Evaluation of non-medical costs associated with visual impairment in four European Countries. PharmacoEconomics. 2006;24(2):193-205. https://doi.org/ 10.2165/00019053-200624020-00007.

8. Newman-Casey PA, Woodward MA, Niziol LM, Lee PP, De LB. Brand medications and medicare part D: how eye care providers' prescribing patterns influence costs. 2018. https://www.ncbi.nlm.nih.gov/ pubmed/28625684. Accessed Apr 2019.

9. Shrank WH, Liberman JN, Fischer MA, Girdish C, Brennan TA, Choudhry NK. Physician perceptions about generic drugs. Ann Pharmacother. 2011;45(1):31-8. https://doi.org/10.1345/aph. 1 p389.

10. Cunningham CT, Quan H, Hemmelgarn B, Noseworthy T, Beck CA, Dixon E, Jetté N, et al. Exploring physician specialist response rates to web-based surveys. BMC Med Res Methodol. 2015;15:1. https://doi.org/10.1186/s12874-015-0016-z.

11. Census Bureau Regions and Divisions with State FIPS Codes, Census Bureau Regions and Divisions with State FIPS Codes1-2. 2000. https://www2. census.gov/geo/pdfs/maps-data/maps/reference/ us_regdiv.pdf. Accessed Apr 2019.

12. Sleath B, Robin AL, Covert D, Byrd JE, Tudor G, Svarstad B. Patient-reported behavior and problems in using glaucoma medications. Ophthalmology. 2006;113(3):431-6. https://doi.org/10.1016/j. ophtha.2005.10.034.

13. Priluck AZ, Dietze J. Ophthalmologist and optometrist glaucoma prescribing patterns based on 2015 medicare part D data. Ophthalmol Glaucoma. 2019;2(1):63-6. https://doi.org/10.1016/j.ogla. 2018.11.009.

14. Slota C, Davis SA, Blalock SJ, Carpenter DM, Muir KW, Robin AL, Sleath B. Patient-physician communication on medication cost during glaucoma visits. Optom Vis Sci. 2017;94(12):1095-101. https://doi.org/10.1097/opx.0000000000001139.

15. Fickweiler F, Fickweiler W, Urbach E. Interactions between physicians and the pharmaceutical industry generally and sales representatives specifically and their association with physicians' attitudes and prescribing habits: a systematic review. BMJ Open. 2017;7:9. https://doi.org/10.1136/bmjopen-2017016408 .

16. Kahook MY, Fechtner RD, Katz LJ, Noecker RJ, Ammar DA. A comparison of active ingredients and preservatives between brand-name and generic topical glaucoma medications using liquid chromatography-tandem mass spectrometry. Curr Eye Res. 2011;37(2):101-8. https://doi.org/10.3109/ 02713683.2011 .631722 .

17. Kolko M, Jensen PK. The physical properties of generic latanoprost ophthalmic solutions are not identical. Acta Ophthalmol. 2017;95(4):370-3. https://doi.org/10.1111/aos.13355.

18. Shrank WH, Cox ER, Fischer MA, Mehta J, Choudhry NK. Patients' perceptions of generic medications. Health Aff. 2009;28(2):546-56. https://doi.org/10.1377/hlthaff.28.2.546.

19. Kellerman S. Physician response to surveys A review of the literature. Am J Prev Med. 2001;20(1):61-7. https://doi.org/10.1016/s0749-3797(00)00258-0. 